\title{
Effects of Attachment-Based Interventions on Maternal Sensitivity and Infant Attachment: Differential Susceptibility of Highly Reactive Infants
}

\author{
Mariska Klein Velderman, Marian J. Bakermans-Kranenburg, Femmie Juffer, \\ and Marinus H. van IJzendoorn \\ Leiden University
}

\begin{abstract}
The current intervention study aimed at breaking the potential intergenerational cycle of insecure attachment. The authors randomly assigned 81 first-time mothers to one of two intervention groups or a control group. The interventions involved four home visits when the infants were between 7 and 10 months old. The first intervention, VIPP, consisted of video-feedback and brochures to enhance sensitive parenting. The second intervention, VIPP-R, involved additional discussions of mothers' childhood attachment experiences in relation to their current caregiving. After the intervention, intervention mothers were more sensitive than control mothers. The interventions were most effective for highly reactive children and their mothers, providing experimental support for Belsky's (1997) hypothesis of highly reactive versus less reactive children's evolutionary based differential susceptibility to rearing influences.
\end{abstract}

Keywords: attachment, maternal sensitivity, intervention, parent-child relationship, temperament, video feedback

Bowlby (1984) stressed the importance of an encouraging, supportive, and stable parental figure during children's early years of life (Ainsworth, Blehar, Waters, \& Wall, 1978) contributing to young children's sense of attachment security and trust in significant others as well as to their sense of self-esteem (Cassidy, 1999; Verschueren \& Marcoen, 1999). Summarizing the myriad of empiric studies on the sequelae of secure and insecure attachments, Sroufe, Egeland, Carlson, and Collins (2005) concluded that the beneficial effects of secure attachments may especially be observed in more harmonious parent-child relationships and in more satisfying close friendships at later stages of development with lawful discontinuities in unstable childrearing circumstances.

Because of the importance of early attachments for the

Mariska Klein Velderman, Marian J. Bakermans-Kranenburg, Femmie Juffer, and Marinus H. van IJzendoorn, Centre for Child \& Family Studies, Leiden University, The Netherlands.

The study was supported by a Pioneer Award of the Netherlands Organization for Scientific Research NWO (Grant PGS 59-256) and the NWO/SPINOZA Prize, both to Marinus van IJzendoorn. We acknowledge the assistance of Philomeen Breddels-van Baardewijk, Marja Duyvesteyn, Lina Kalinauskiene, Hesther van Leeuwen, Paulette Steenblok, and Martine Terstegen in collecting and coding data.

Correspondence concerning this article should be addressed to Marian J. Bakermans-Kranenburg or Femmie Juffer, Centre for Child \& Family Studies, Leiden University, P.O. Box 9555, 2300 RB Leiden, The Netherlands. E-mail: bakermans@fsw.leidenuniv.nl or juffer@fsw.leidenuniv.nl child's current and future functioning in close relationships, it is crucial to investigate whether child's attachment security could be enhanced. Parental sensitivity, that is parents' ability to perceive signals accurately and to respond to them promptly and adequately, has been shown to affect the development of attachment security in a consistent, albeit modest, way (Ainsworth et al., 1978; De Wolff \& Van IJzendoorn, 1997). Meta-analytic results (Van IJzendoorn, 1995) also demonstrated that parents' mental representations of attachment (i.e., the perception of their childhood attachment experiences and the influence on current psychosocial functioning; Hesse, 1999) partly determine their sensitivity to the children's attachment signals. Both parental sensitivity and parental attachment representations therefore seem promising candidates for preventive intervention efforts (Juffer, Bakermans-Kranenburg, \& Van IJzendoorn, 2005a).

Several intervention studies have been implemented that successfully enhanced parental sensitivity and prevented or altered insecure attachments in young children (e.g., Anisfeld, Casper, Nozyce, \& Cunningham, 1990; Heinicke, Fineman, Ruth, Recchia, Guthrie, \& Rodning, 1999). In their meta-analyses on the effectiveness of the various types of attachment-based interventions Bakermans-Kranenburg, Van IJzendoorn, and Juffer (2003) found that interventions focused on sensitivity and/or attachment were most effective if the intervention sessions were aimed at sensitive parenting behavior and included only a moderate number of sessions ("less is more") whether or not the families involved were facing multiple problems. From the perspective of a causal role of parental sensitivity in the emergence of 
(in-)secure attachments, it should also be noted that interventions successfully enhancing parental sensitivity were accompanied by positive, albeit somewhat smaller, effects on attachment security. This is one of the reasons why a behaviorally focused attachment-based intervention with a small number of intervention sessions was implemented in the current study.

In contrast with the large number of interventions aiming at enhancing parental sensitivity, there are few intervention studies that implicitly or explicitly address the issue of changing parental mental representations of attachment (e.g., Lieberman, Weston, \& Pawl, 1991). Only one intervention evaluated its effect on parental attachment representations (Egeland, Adam, Ogawa, \& Korfmacher, 1995). The absence of positive changes in mothers' representations of attachment in that study may have been related to the rather high percentage of secure mothers as well as secure infants in their control group (i.e., "ceiling effect"). Thus, unfortunately, no firm conclusions regarding the (failing) effectiveness of interventions on parental attachment representations can be drawn.

One could imagine that interventions enhancing parental attachment security might create more firmly rooted behavioral changes in the parent and therefore achieve a more persistent change in children's attachment security. In interventions with a behavioral focus, mothers receive suggestions about how to respond to the attachment signals of their child at a certain age, for example, infancy, like in the case of the current study. Parents may not be able to attune themselves to their growing child when their inner working model of attachment has remained insecure. Parents with an insecure attachment representation might find it particularly challenging to combine sensitive responses to attachment signals with setting limits when the child is misbehaving and persists in disobedience. Secure attachment representations might help parents to flexibly adapt to the changing behavioral repertoire of the child and to find sensitive solutions to developmental issues with which the child is struggling, because empathy with the child's perspective will be facilitated. Therefore, we hypothesize that a combination of enhancement of parental sensitivity and parental attachment representations may lead to firmer and more persistent changes in children's attachment security.

Fraiberg, Adelson, \& Shapiro (1975) pointed out how "ghosts in the nursery" can play a crucial role in daily family life across generations. The metaphor of "ghosts in the nursery" suggests that past attachment experiences may, although unnoticed, interfere with caregiving and, in some families, take over and control the lives of several generations while the past is allowed to repeat itself. In the current intervention study, we attempted to help parents restructure their current attachment representations by discussing their early attachment experiences and by exploring the link between those experiences and the developing relationship with their first-born baby. Mothers of first-born infants were recruited on the basis of their insecure mental representation of their own childhood attachment experiences. To our knowledge, this intervention study is the first to include mothers who have been selected on the basis of their attachment representation.

The intervention was implemented between the seventh and the tenth month of the baby's age. Children's attachment relationship to their caregiver is thought to emerge and become more firmly established during the second half year after birth (Bowlby, 1984; Marvin \& Britner, 1999). Parents may be open to suggestions for change during a period when they realize that raising a baby creates problems that they might not be able to solve without assistance and interactive routines have not yet become fixed. Moreover, they may be more open to intervention activities and suggestions in the second half of the first year than in the period immediately after birth when adapting to new demands (see for meta-analytic support, Bakermans-Kranenburg et al., 2003).

In the meta-analytic review of attachment-based intervention studies (Bakermans-Kranenburg et al., 2003), age (below or over 6 months) was the only child characteristic leading to significantly different intervention effects, although some interventions included children with various temperamental, socioemotional, and communicative problems (e.g., anxious-withdrawn; irritable). This is rather unexpected in view of the fact that there are strong, evolutionary reasons to emphasize the "differential susceptibility" of children to the child rearing influences of their parents. As Belsky (2005) contended:

Because the future is inherently uncertain, the goals that parents have for their children, whether held consciously or unconsciously, could turn out to have huge reproductive costs if (a) realized by all their children and (b) future conditions turn out to be highly unlike those that parents, again consciously or unconsciously, anticipate. For this reason it seems to make evolutionary sense for children, especially within a family, to vary in their susceptibility to parental rearing, with some being highly responsive and others being less responsive and perhaps not responsive at all. A growing body of evidence which is not inconsistent with this view suggests, interestingly, that it may be highly negatively emotional infants who are most susceptible to parental influence-for better (when receiving emotionally supportive care) or for worse (when receiving less supportive care). (Belsky, 2005, p. 176; see also Belsky, 1997)

With this in mind, the current study tested the potentially differential effectiveness of our intervention for children with high versus average to low negative reactivity.

In short, in a randomized control group trial, we implemented two types of short-term attachment-based interventions with insecure mothers and their first-born infants. The first type, at the behavioral level, focused on enhancing mothers' sensitive responsiveness by providing them with video feedback about their own (in-)sensitive behaviors. The second intervention, at the representational level, aimed to both enhance sensitivity and restructure mothers' attachment representation. We provided mothers in this group with video feedback and additional discussions about their childhood attachment experiences.

The first hypothesis was that both our interventions would be effective in improving the mothers' sensitive responsiveness and that the combination of behavioral and representational approaches may be the most effective. The 
second hypothesis was that we expected to find positive effects of the interventions on infant attachment security. However, based on previous (meta-analytic) studies, we expected effect sizes for infant attachment security to be smaller than the effects on parental sensitivity. Finally, our third hypothesis was that highly reactive children will be more susceptible to their mothers' sensitivity and changes in maternal sensitivity than less reactive children and that the mothers of children characterized by high negative reactivity will profit most from the intervention. The differential intervention effects for highly reactive children compared with less reactive children is an experimental test of Belsky's (2005) model of differential susceptibility to childrearing influences.

\section{Method}

\section{Participants}

Mothers with first-born 4-month-old children were identified by using town hall records of a city in the western part of The Netherlands and by using the records of the children's health centers in five neighboring villages. By means of phone calls, mothers with more than 8 but less than 14 years of formal education were selected. Our assumption was that parenting information and other resources were less available to these mothers than to higher-educated women (Viswanath, Kahn, Finnegan, Hertog, \& Potter, 1993). Selected mothers $(n=311)$ were invited to the institute to participate in an interview about their childhood-the Adult Attachment Interview (AAI; George, Kaplan, \& Main, 1985; Hesse, 1999) — as part of a study regarding child development and the influence of parents' own childhood on the development of their children. Subsequently, 262 AAIs were administered (16\% attrition) in the selection procedure (Bakermans-Kranenburg, Juffer, \& Van IJzendoorn, 1998). To facilitate timely intervention, the interviews were not transcribed; instead, a tentative attachment classification was assigned on the basis of the audiotaped AAI by the second and fourth authors (see subsequently). From the mothers who participated in the AAI, 84 mothers $(32 \%$ of 262$)$ tentatively classified as insecure were included in this study. Three mothers only participated in the pretest home visit (3.6\% attrition), one because of the child's illness and two because of lack of time. The present article focuses on the 81 mothers who participated in all activities. Participants did not get paid for participating in our study.

Mothers who were tentatively coded as dismissing or preoccupied, regardless of an additional classification as unresolved (Hesse, 1999), were included. They were randomly assigned to one of three groups: (a) a control group $(n=27)$; (b) a group with written information about sensitive parenting and personal video feedback (hereinafter referred to as the VIPP group, $n=28$ ); and (c) a group with written information about sensitive parenting, personal video feedback, and additional discussions about early attachment experiences (hereinafter referred to as the VIPP-R group, $n=26$ )

The mothers' mean age was 27.8 years (standard deviation [SD] $=3.63)$, and their mean educational level was $2.51(S D=0.96)$ on a scale ranging from 1 to 4 , with $1=$ primary school or junior secondary vocational education and $4=$ senior secondary general education followed by senior secondary vocational education. Control mothers were on average 2 years older than intervention mothers $(t[78]=2.72, p<.01)$. The two groups did not differ on educational level or on intelligence.

\section{Procedure}

The first home visit in both the control group and the intervention groups took place at $6.83(S D=1.03)$ months of the child's age and typically lasted 1 hour 30 minutes (BakermansKranenburg et al., 1998). During this visit, the home visitor introduced herself to the mother and explained the procedure. In the two intervention groups, the home visitor explicitly asked permission for four further home visits. Video observations were made of the mother-infant dyads to assess sensitive responsiveness during free play. Thus, both intervention mothers and control mothers experienced filming in the home during mother-infant interactions

The first home visit and the intervention sessions were implemented by three female home visitors (including the second and third authors) with a university degree in education and child studies who knew that the respondents had been selected on the basis of their insecure attachment representation but were unaware of the mothers' type of insecurity and of all other information about the mothers or infants enrolled in the intervention. The second author only worked with mothers for whom she had not coded the AAI in the selection procedure. The intervention sessions took place between the babies' seventh and tenth months of age. At 11 months, video-recorded observations of the motherinfant dyads at home were made by a research assistant unknown to the mother to assess the mother's sensitive responsiveness. At 13 months, the mothers were invited to the institute with their child to assess the quality of the infant-mother attachment in the Strange Situation Procedure and to observe the mothers' sensitive responsiveness during free play.

\section{Measures}

Representation of attachment. George, Kaplan, and Main (1985) developed the AAI to measure the quality of adults' attachment representations. The interview can be conceptualized as presenting the respondent with two central tasks: first, to produce and reflect on memories involving early relationships, and second, maintaining coherent, collaborative discourse (Hesse, 1999). Secure or autonomous (F) adults are able to keep this balance. These adults present and evaluate their memories in a coherent and consistent way. Because security is inferred from narrative coherence, supportive as well as apparently difficult family backgrounds can be associated with a secure classification (Hesse, 1999).

The narratives of dismissing (Ds) adults lack coherence. These adults tend to minimize the significance of attachment-related experiences in their narratives. Preoccupied (E) adults display either angry or passive preoccupation with attachment figures or attachment-related experiences (Hesse, 1999). An additional classification as unresolved (U) is assigned when there are momentary lapses in the monitoring of reasoning or discourse during the discussion of traumatic experiences such as loss or abuse. Several studies have shown the AAI's reliability and validity (for a metaanalytic validation, see Van IJzendoorn, 1995). In our study, the AAI was only used as a selection instrument. Mothers were selected on basis of their insecure attachment representation. The second and fourth authors, both trained by and reliable with Main and Hesse, assigned a tentative classification to the interviews on the basis of the audiotaped interviews.

Sensitive responsiveness. Maternal sensitive responsiveness is defined as the mother's ability to perceive her baby's signals accurately, and to respond to them promptly and appropriately (Ainsworth, Bell, \& Stayton, 1971, 1974). Sensitive responsiveness was assessed on the basis of 10 minutes of free play, at home at 6 months and 11 months of the baby's age, and at the institute 
when the infants were 13 months old. Mothers were instructed to play with their infants as they liked. Each mother was provided with the same collection of toys (e.g., a mirror, rattles). Scores for the three sessions were independently assigned using the Ainsworth's rating scale for sensitivity (Ainsworth et al., 1974) ranging from (1) highly insensitive to (9) highly sensitive. Coders were unaware of other data concerning the respondents. Intercoder reliabilities were high (mean intraclass correlation .84, range .83$.86, n=25)$. Posttest sensitivity scores (11 and 13 months) were significantly correlated $(r=.45, p<.001)$; therefore, aggregated mean scores for maternal posttest sensitivity were used in subsequent analyses.

Infant-mother attachment. Infant-mother attachment was observed in the Strange Situation procedure (SSP, Ainsworth et al., 1978) when the children were 13 months old. The procedure involves a series of episodes in which the infant is exposed to mildly stressful events: the entrance of a stranger and two separations from the parent followed by a reunion. The infants' patterns of attachment behavior were classified as secure (B), insecureavoidant (A), or insecure-resistant (C). Infants classified as disorganized (D; Main \& Solomon, 1990) were forced into an alternative classification as A, B, or C. All SSPs were coded by the second or fourth author. They were not aware of other information concerning the dyads. Intercoder reliability was adequate $(92 \%$, kappa $=.73$ for the three-way A, B, C classifications; $88 \%$, kappa $=.82$ for the four-way A, B, C, D classifications, $n=25$ ). Using the simplified Richters, Waters, and Vaughn (1988) algorithm, continuous scores for attachment security (Van IJzendoorn \& Kroonenberg, 1990) were computed on the basis of the interactive SSP scale scores for proximity-seeking, contactmaintaining, resistance, and avoidance. The intercoder reliability for these continuous security scores was adequate, intraclass correlation .76 ( $n=14$; single measure, absolute agreement).

Temperament. Temperament of the infants was assessed using the Dutch translation of the Infant Behavior Questionnaire (IBQ, Rothbart, 1981). The mothers completed this questionnaire during their visit to the institute in the selection stage of the study, when the infants were on average 6.05 months $(S D=1.17)$ old. The IBQ consists of six subscales: Activity level, Smiling and Laughter, Fear, Distress to Limitations, Soothability, and Vocal Activity. Like in Rothbart (1986) a seventh scale, Overall Reactivity, was computed by subtracting the standardized scores on Smile and Laughter $(\alpha=.73)$ and Activity $(\alpha=.72)$ from the standardized score on Distress to Limitations $(\alpha=.64)$.

Belsky (2005) suggested that highly negatively emotional infants may be more susceptible to rearing influences. From an evolutionary perspective, it seems implausible that the majority of infants would be born extremely susceptible to rearing influences (Belsky, 1997). To test the differential susceptibility hypothesis, we chose an a priori split that was meant to separate the most reactive children from the children with moderate or low reactivity. In Van den Boom's (1994) intervention study among lowerclass mothers and their irritable infants, $17 \%$ of 6-month-old infants were found to be irritable. This is congruent with the borderline/clinical cutoff for children scoring above the 82.7th percentile as used for the Child Behavior Checklist (CBCL; Achenbach, 1991). Therefore, we considered infants with scores on Overall Reactivity at or above the 80th percentile $(>1.36)$ as highly reactive $(n=17)$. The remaining 64 infants, scoring below the 80th percentile, were considered less reactive.

\section{Intervention}

Intervention efforts in the VIPP group were directed at stimulating and reinforcing maternal sensitivity by means of brochures about sensitive parenting and personalized video feedback (for a detailed protocol, see Juffer, Bakermans-Kranenburg, \& Van IJzendoorn, in press). In the VIPP-R group, additional discussions about the mother's attachment experiences took place, aimed at affecting her representation of attachment, VIPP with a representational focus. Both interventions took place during four home visits of, on average, 1 hour 30 minutes (in the VIPP group) to 3 hours (in the VIPP-R group) each with intervening periods of 3 to 4 weeks.

The main structure of each intervention session was outlined in an intervention protocol (Juffer et al., in press). Each session started with making the videotape that would be used during the next intervention session. These videotaped mother-infant interactions were standardized in the four intervention sessions and involved, for instance, the mother bathing the infant. The recordings were for use in the next intervention session so that the mother-infant dyad would not be filmed immediately after the video feedback. After making the videotape, the video feedback intervention was implemented using the videotape from the previous session followed by the attachment discussions in the VIPP-R group. The home visitors prepared the video feedback in the period between home visits, selecting specific episodes they wanted to bring to the mother's attention and preparing pertinent comments to these episodes. Regularly, intervention experiences were discussed with the fourth author, who was also blind to the specific information collected on the mother-infant dyads.

In each intervention session, video feedback was implemented around a specific theme. For example, baby's contact-seeking and exploration behavior was central to the first intervention session. In addition, mothers received two brochures about crying and comforting. More details of the video feedback program are outlined elsewhere (e.g., Bakermans-Kranenburg et al., 1998; Juffer et al., in press). The mothers in the VIPP-R group also participated in discussions conceiving the mother's past attachment experiences and the possible influences of these past experiences on her parenting style (VIPP-R; Juffer et al., in press). These discussions took place after the video feedback. They were initiated by using questionnaires or projective material as detailed in the intervention protocol. Discussions were inspired by attachment theory (Bowlby, 1988) and by the biographies of so-called "earned secure" persons (Pearson, Cohn, Cowan, \& Cowan, 1994). Earnedsecure people describe their childhoods as unloving and hard, but they have been able to restructure their thoughts and feelings regarding their childhood experiences and can coherently reflect on them without becoming angry or confused and without diminishing the effects of their negative experiences on their personality. Again, each of the intervention sessions had its own theme, for example, past and present separations in the first session. After each session, the home visitors noted their impression of the session, the mother's reaction to the intervention, as well as peculiarities of the interaction of the mother and child involved. For a more detailed description of the activities and process of each session, see Juffer et al. (in press) and Klein Velderman, Bakermans-Kranenburg, Juffer, and Van IJzendoorn (in press).

\section{Results}

\section{Intervention Effects on Maternal Sensitivity}

No significant difference in sensitivity between intervention and control mothers was found at the pretest $(t[79]=$ $0.56, p=.58)$. At the posttest, intervention mothers were significantly more sensitive than control mothers $(t[79]=$ $2.14, p<.05, d=0.49)$. Univariate analysis of variance 
with pretest sensitivity as covariate showed that sensitivity of intervention mothers increased significantly more than control mothers' sensitivity $(F[1,78]=4.21, p<.05, d=$ 0.46) (see Figure 1). Post hoc analyses showed that this was also true for both posttests separately at 11 and at 13 months. Mothers' posttest sensitivity in both intervention groups was significantly higher than in the control group (for the VIPP group, $t[53]=1.70, p<.05$ [one-tailed], $d=$ 0.46 , for the VIPP-R group $t[51]=1.89, p<.05$ [onetailed], $d=0.52$ ), and the effectiveness of the two types of interventions did not differ.

\section{Intervention Effects on Children's Attachment Security}

The intervention was less effective in changing children's attachment security. Although $67 \%$ of the infants in the intervention groups developed a secure attachment to their mothers, the same was true of $56 \%$ of the infants in our control group $\left(\chi^{2}[1, N=81]=0.95, p=.17\right.$ [one-tailed], $d=0.22$ ). In the VIPP group, $71 \%$ of the children were secure and in the VIPP-R group $62 \%$ of the children were secure. The number of secure infants in both intervention groups was not significantly higher than in the control group (for the VIPP group $\chi^{2}[1, n=55]=1.50, p=.11$ [one-tailed], $d=0.33$, and for the VIPP-R group, $\chi^{2}[1, n=$ 53 ] $=0.20, p=.33$ [one-tailed], $d=0.12$ ). The effectiveness of the two types of interventions did not differ.

Using the continuous attachment security score, we found no significant intervention effect $(t[79]=0.43, p=.33$ [one-tailed], $d=0.10$ ). Contrasting the VIPP group with the control group, we did not find a significant intervention effect either $(t[53]=1.08, p=.14$ [one-tailed], $d=0.29)$. Infants in the VIPP-R group were also not significantly more secure than the infants in the control group $(t[51]=$ $-0.31, p=.76, d=-0.08$ ).

The infants of intervention mothers who showed more increase in sensitivity were more securely attached (using the continuous security scores). In the intervention group, the correlation between change in pre- to posttest maternal sensitivity and posttest infant security amounted to $r(53)=$ $.25, p=.04, d=0.52$.

\section{Intervention Effects: Differential Susceptibility}

To examine Belsky's differential susceptibility hypothesis, we first tested the effectiveness of the intervention for the highly reactive infants and their mothers. An analysis of variance on posttest sensitivity with the intervention and higher versus lower infant reactivity as factors showed a significant interaction effect $(F[1,77]=4.17, p<.05, d=$ 0.47). Mothers of highly reactive infants profited more from the intervention than the others. At posttest, sensitivity in the highly reactive intervention group (mean $=5.37 ; S D=$ 0.93 ) differed significantly from sensitivity in the highly reactive control group $($ mean $=3.57 ; S D=0.63)(t[15]=$ 3.94, $p<.01, d=2.27$ ). Posttest sensitivity in the less reactive intervention group (mean $=5.67 ; S D=1.21)$ did not differ significantly from sensitivity in the less reactive control group $($ mean $=5.30 ; S D=1.31)(t[62]=1.12, p=$ $.13, d=0.29$ ) (see Figure 2). This differential intervention effect could not be ascribed to differences in pretest sensitivity between the mothers of highly reactive infants (mean $=4.24, S D=1.49$ ) and the mothers of the less reactive infants $($ mean $=4.23, S D=1.21)(t[79]=0.01$, $p=.99$ ).

In an analysis of variance on the continuous attachment security score with the intervention and higher versus lower reactivity as factors, the interaction was not significant $(F[1$, $77]=1.52, p=.11, d=0.28$ ). Highly reactive infants in the intervention group did not differ significantly in attachment security (mean $=.84 ; S D=2.52$ ) from highly reactive control group infants (mean $=-.97 ; S D=1.32)(t[15]$ $=1.50, p=.08$ [one-tailed], $d=0.90$ ) (see Figure 2).

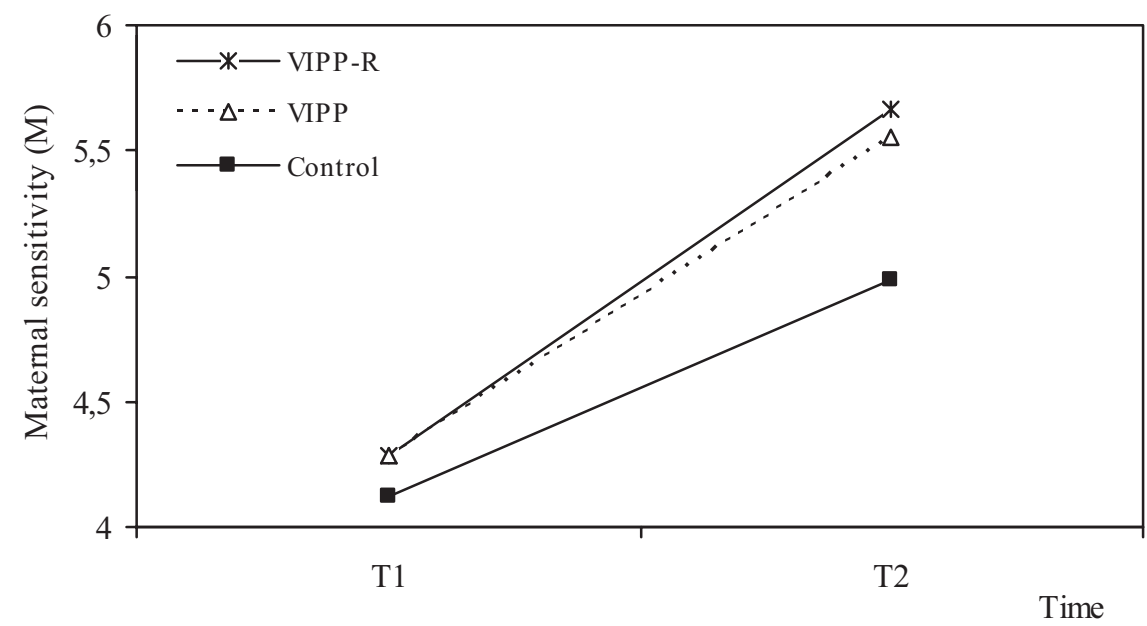

Figure 1. Increases in mothers' mean level of sensitive responsiveness from $\mathrm{T}_{1}\left(6\right.$ months) to $\mathrm{T}_{2}$ (11-13 months) in the VIPP, VIPP-R, and control groups. See Participants section for a description of the groups. 


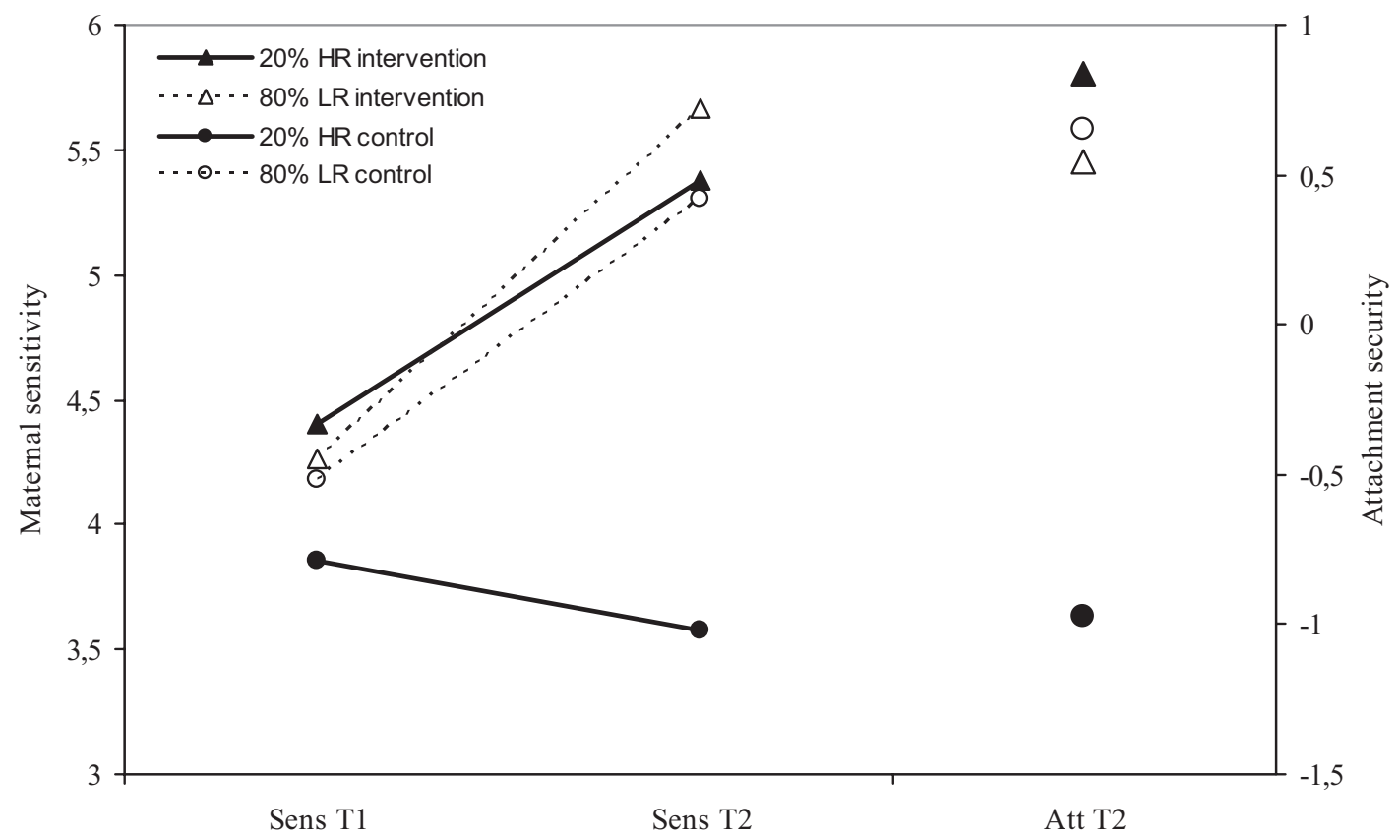

Figure 2. Increases in mothers' mean level of sensitive responsiveness from $\mathrm{T}_{1}$ (6 months) to $\mathrm{T}_{2}$ (average of 11 and 13 months), and infants' mean level of attachment security at $\mathrm{T}_{2}$ (13 months) in the intervention groups $(n=54)$ and control group $(n=27)$ for the $20 \%$ highly (HR) and $80 \%$ less reactive (LR) infants.

Attachment security in the less reactive intervention group (mean $=.54 ; S D=2.63)$ did not differ from attachment security in the less reactive control group $(M=0.65 ; S D=$ 2.79) $(t[62]=0.14, p=.89$ [two-tailed], $d=0.04)($ see Figure 2).

\section{Differential Susceptibility to Maternal Sensitivity and Changes in Maternal Sensitivity}

No differential intervention effects were found on infant attachment security. It should be noted, however, that the intervention was not aimed directly at the children, but at their mothers. Therefore, our analysis of direct intervention effects on the children might not be the most critical test of Belsky's differential susceptibility hypothesis. In addition, therefore, as a second test of Belsky's differential susceptibility hypothesis, we tested whether highly reactive infants were more susceptible to their mothers' sensitivity and changes in maternal sensitivity. In the group of highly reactive intervention infants, attachment security and change in pre- to post-test maternal sensitivity were significantly correlated, $r=.64(p=.01, n=12)$. In the less reactive intervention group, the correlation was $r=.11$ $(p=.24, n=.42)$. The difference in correlations was significant $(p=.04)$. The most reactive infants were more susceptible to their mothers' change in sensitivity. In the group of highly reactive infants, attachment security and change in pre- to posttest maternal sensitivity were significantly correlated, $r(16)=.57, p=.02$. In the less reactive intervention group, the correlation was $r(63)=.08(p=$
.53). The difference in correlations was significant $(p=$ $.03)$. The most reactive infants were more susceptible to their mothers' change in sensitivity.

\section{Discussion and Conclusion}

In the present study, we found experimental evidence supporting the differential susceptibility of highly reactive infants and their mothers to changes in the (caregiving) environment. In a randomized control group trial, we provided the mothers of first-born infants with video feedback and written information about parenting to enhance sensitive parenting and involved some of the mothers additionally in discussions about their childhood attachment experiences in relation to their current caregiving. These two interventions were equally effective in enhancing maternal sensitivity to the infants but failed to produce a significant effect on infant attachment security.

The interventions were most effective for mothers of highly reactive children, and although the attachment security of highly reactive children did not change more as a consequence of the intervention, the experimentally induced change in maternal sensitivity appeared to impact more strongly on attachment security in the highly reactive infant group. That is, for highly reactive infants, attachment security was significantly associated with their mothers' gains in sensitivity between pre- and posttest. This was not true for low reactive infants; their attachment security was not related to improvements in sensitivity of their mothers. Thus, the most demanding test of the differential susceptibility 
hypothesis confirmed the prediction that highly reactive children are more susceptible to experimentally induced environmental change than less reactive infants.

To our knowledge, these outcomes constitute the first experimental support for Belsky's (1997) hypothesis of children's evolutionary based differential susceptibility to rearing influences in the domain of sensitivity and attachment. Previous studies showed differential susceptibility of mothers of irritable infants to the positive effects of social support (Crockenberg, 1981); the larger effect of gentle parental discipline, deemphasizing power on compliance, in more fearful children (Kochanska, 1995); the effectiveness of an attachment-based intervention on irritable infants and their low socioeconomic status mothers (Van den Boom, 1994); and on anxiously withdrawn children (LaFreniere \& Capuano, 1997).

More conclusive evidence is likely to be generated by studies that experimentally manipulate the environment for infants who differ in emotional reactivity. For example, in a cross-fostering experiment on rhesus monkeys Suomi (1999) found that control infants with normative patterns of reactivity displayed normal developmental patterns independent of the relative nurturance of their foster mother. In contrast, highly reactive infants only showed normal or optimal patterns of development in cases of cross-fostering to nurturing females. Drawing on data from the Infant Health and Development Program, in which low birth weight, premature infants from economically disadvantaged homes were randomly assigned to experimental and control treatment conditions, Blair (2002) found that infants who were highly negatively emotional and assigned to the early intervention treatment group scored substantially lower on externalizing problems at 3 years of age than did similarly tempered control infants with no such treatment effect proving detectable in the case of other infants with less negative emotionality.

Similarly, but in a different domain, highly reactive children in the present study were more susceptible to experimentally induced changes in maternal sensitivity than less reactive infants. Moreover, their mothers profited more from the intervention. We suggest that mothers of highly reactive infants may be more readily reinforced by their infants' positive behavioral changes in the dyadic context. As an alternative interpretation, we speculate that mothers of highly reactive children may be more susceptible to environmental influences because they are more reactive themselves, because emotional reactivity has been found to be substantially genetically determined (Bokhorst et al.; Goldsmith, Lemery, Buss, \& Campos, 1999).

The extension of the differential susceptibility hypothesis to both children and their parents would broaden Belsky's evolutionary model to the dyadic level. In future research, infant as well as maternal reactivity should be included to build on our findings and broaden insights into the interplay among attachment, temperament, and maternal behavior. Surprisingly, mothers of less reactive infants in the control group displayed an increase in sensitivity that appeared to be similar to that of mothers in the intervention group. We hypothesize that this could be a result of filming of parent- child interaction during the pre- and posttest in the control group (although they received the videotapes only after the posttest sessions).

Our intervention study confirmed the conclusions of a recent meta-analysis on attachment-based interventions that a moderate number of sessions and a clear behavioral focus may yield large effect sizes ("less is more"; BakermansKranenburg et al., 2003). The meta-analysis included, however, only four sensitivity-focused randomized interventions with fewer than five intervention sessions in multirisk families. This study therefore is an important contribution to the small number of experimental studies in this domain. Four extensive home visits with video feedback (and representational discussions) led to significant enhancement of maternal sensitivity and tended to improve the attachment relationship with the infants. Our results reflect the metaanalytic finding that it is more difficult to improve attachment security than it is to enhance maternal sensitivity.

On the other hand, we also found support for the metaanalytic finding that studies with large effect sizes on maternal sensitivity also effectively promote infant attachment security. In our study, larger increases in maternal sensitivity were associated with more improvement in attachment security. In the meta-analysis, however, it was impossible to test the difference in effectiveness of interventions including emotionally reactive children as compared with interventions focusing on less reactive children as a result of the small number of the former studies. In our intervention study, we showed that highly reactive infants and their mothers are more susceptible to the influence of the intervention sessions and that the intervention effectiveness for the less reactive infants was much less impressive. Diverging outcomes of previous intervention experiments may be related to differential susceptibility for environmental influences of the specific type of children involved. Our study shows that parents of highly reactive infants may be the most rewarding targets of intervention efforts even when the number of sessions is rather small.

The current intervention study is limited because of the size of the sample and the way in which infant reactivity was assessed. Despite the fact that a brief home-based intervention in a sample of 81 families entails considerable effort to implement, the power of some statistical analyses may be inadequate. A larger sample might have resulted in a significant interaction effect instead of a trend for intervention effects on attachment security for highly versus less reactive infants. The same is true for the intervention effects on attachment security. We found $56 \%$ secure infants in the control group compared with $67 \%$ in the intervention groups. This corresponds to an effect size of $d=0.22$, which equals the effect size of 0.24 for random studies of less than five sessions in multiproblem samples reported in the meta-analysis of Bakermans-Kranenburg et al. (2003). A sample that was three times larger than the current sample and showed the same attachment distribution would have resulted in a significant difference in proportions between infants in the control and intervention groups $(z=1.69, p<$ .05 [one-tailed]). Still, we found significant outcomes for 
the most crucial hypotheses and converging trends for some less central issues.

We consider the use of Rothbart's (1981) Infant Behavior Questionnaire a second limitation. The IBQ has been used in numerous studies on children's temperament, and it has been thoroughly validated. Bridges, Palmer, Morales, Hurtado, and Tsai (1992) found significant convergence between the IBQ and the observational Goldsmith and Rothbart Laboratory Temperament Assessment Battery (Goldsmith \& Rothbart, 1996). Besides, Weinfield, Whaley, and Egeland (2004) hypothesized that in the context of the attachment relationship, "maternal perceptions may be just as relevant as the child's actual behavior, because maternal perceptions may influence how she interacts with her child" (p. 90). Nevertheless, observational assessment of negative reactivity may be more reliable and valid, and lead to stronger results with less error variance. In future studies on differential susceptibility of highly reactive children, observational procedures (e.g., Goldsmith \& Rothbart, 1996) should be used.

Lastly, the selection of the mothers on the basis of the AAI from audiotape may not have led to a sample with $100 \%$ insecure mothers. In fact, the percentage of securely attached control infants was rather high (56\%), which may have led to a ceiling effect for our intervention. In a completely insecure sample, the possibility of an improvement in maternal sensitivity and infant attachment security would have been larger. Assigning classifications to AAIs from tape instead of transcript may not be sufficiently valid. It would be useful to validate this approach by classifying the AAIs from transcript and comparing the classifications with those made from audiotape.

Our study may be important for mental health providers planning and implementing intervention or prevention programs. To begin with, we found support for the effectiveness of a short-term video feedback intervention. Only four intensive intervention home visits led to significant increases in positive parenting. It thus seems promising and cost-effective to implement brief interventions with a clear focus. Our findings are in line with recent meta-analytic findings (Bakermans-Kranenburg et al., 2003) and extend previously demonstrated effectiveness of video feedback intervention in adoptive samples (Juffer, Hoksbergen, Riksen-Walraven, \& Kohnstamm, 1997; Juffer, BakermansKranenburg, \& Van IJzendoorn, 2005b) to a group of insecure first-time mothers. In particular, mothers of highly reactive infants profit from the intervention. Mothers of highly reactive infants thus seem to be important targets for short-term intervention efforts.

In future intervention studies on differential susceptibility, it is important to test the long-term effectiveness of interventions with highly reactive children. Larger samples may be needed to discriminate the effectiveness of different types of interventions for different kinds of parents and children. The current intervention study provides experimental support for the revolutionary but speculative concept of differential susceptibility to rearing influences of highly versus less reactive infants and, at the same time, documents the implications of differential susceptibility for attachmentbased intervention studies.

\section{References}

Achenbach, T. M. (1991). Manual for the Child Behavior Checklist/4-18 and 1991 Profile. Burlington: University of Vermont, Department of Psychiatry.

Ainsworth, M. D. S., Bell, S. M., \& Stayton, D. J. (1971). Individual differences in Strange Situation behavior of one-year-olds. In H. R. Schaffer (Ed.), The Origins of Human Relations (pp. 17-56). London: Academic Press.

Ainsworth, M. D. S., Bell, S. M., \& Stayton, D. J. (1974). Infantmother attachment and social development: Socialization as a product of reciprocal responsiveness to signals. In M. P. M. Richards (Ed.), The Integration of a Child Into a Social World (pp. 99-135). London: Cambridge University Press.

Ainsworth, M. D. S., Blehar, M. C., Waters, E., \& Wall, S. (1978). Patterns of Attachment: A Psychological Study of the Strange Situation. Hillsdale, NJ: Erlbaum.

Anisfeld, A., Casper, V., Nozyce, M., \& Cunningham, N. (1990). Does infant carrying promote attachment? An experimental study of the effects of increased physical contact on the development of attachment. Child Development, 61, 1617-1627.

Bakermans-Kranenburg, M. J., Juffer, F., \& Van IJzendoorn, M. H. (1998). Intervention with video feedback and attachment discussions: Does type of maternal insecurity make a difference? Infant Mental Health Journal, 19, 202-219.

Bakermans-Kranenburg, M. J., Van IJzendoorn, M. H., \& Juffer, F. (2003). Less is more: Meta-analysis of sensitivity and attachment interventions in early childhood. Psychological Bulletin, 129, 195-215.

Belsky, J. (1997). Theory testing, effect-size evaluation, and differential susceptibility to rearing influences: The case of mothering and attachment. Child Development, 68, 598-600.

Belsky, J. (2005). The developmental and evolutionary psychology of intergenerational transmission of attachment. In C. S. Carter, L. Ahnert, K. E. Grossmann, S. B. Hrdy, M. E. Lamb, S. W. Porges, \& N. Sachser (Eds.), Attachment and Bonding: A New Synthesis (pp. 169-178). Cambridge, MA: MIT Press.

Blair, C. (2002). Early intervention for low birth weight, preterm infants: The role of negative emotionality in the specification of effects. Development and Psychopathology, 14, 311-332.

Bokhorst, C. L., Bakermans-Kranenburg, M. J., Fearon, P., Van IJzendoorn, M. H., Fonagy, P., \& Schuengel, C. (2003). The importance of shared environment in mother-infant attachment A behavior-genetic study. Child Development, 74, 1769-1782.

Bowlby, J. (1984). Attachment and Loss. Vol. 1: Attachment (Revised Ed.). London: Penguin Books.

Bowlby, J. (1988). A Secure Base: Clinical Applications of Attachment Theory. London: Routledge.

Bridges, L. J., Palmer, S. A., Morales, M., Hurtado, M., \& Tsai, D. (1992). Agreement between affectively based observational and parent-report measures of temperament at infant age 6 months. Infant Behavior and Development, 16, 501-506.

Cassidy, J. (1999). The nature of the child's ties. In J. Cassidy \& P. R. Shaver (Eds.), Handbook of Attachment: Theory, Research, and Clinical Applications (pp. 3-20). New York: Guilford Press.

Crockenberg, S. B. (1981). Infant irritability, mother responsiveness, and social support influences on the security of infantmother attachment. Child Development, 52, 857-865.

De Wolff, M. S., \& Van IJzendoorn, M. H. (1997). Sensitivity and attachment: A meta-analysis on parental antecedents of infant attachment. Child Development, 68, 571-591. 
Egeland, B., Adam, E., Ogawa, J., \& Korfmacher, J. (1995, April). Adult attachment: Implications for the therapeutic process in a home visitation intervention. Paper presented at the biennial meeting of the Society for Research in Child Development, Indianapolis, IA.

Fraiberg, S., Adelson, E., \& Shapiro, V. (1975). Ghosts in the nursery: A psychoanalytic approach to the problems of impaired infant-mother relationships. Journal of the American Academy of Child Psychiatry, 14, 387-422.

George, C., Kaplan, N., \& Main, M. (1985). Adult Attachment Interview. Unpublished manuscript, University of California, Berkeley.

Goldsmith, H. H., Lemery, K. S., Buss, K. A., \& Campos, J. J. (1999). Genetic analyses of focal aspects of infant temperament. Developmental Psychology, 35, 972-985.

Goldsmith, H. H., \& Rothbart, M. K. (1996). Laboratory Temperament Assessment Battery (LAB-TAB): Prelocomotor and Locomotor Versions. Madison: University of Wisconsin.

Heinicke, C. M., Fineman, N. R., Ruth, G., Recchia, S. L., Guthrie, D., \& Rodning, C. (1999). Relationship-based intervention with at-risk mothers: Outcome in the first year of life. Infant Mental Health Journal, 20, 349-374.

Hesse, E. (1999). The Adult Attachment Interview: Historical and current perspectives. In J. Cassidy \& P. R. Shaver (Eds.), Handbook of Attachment: Theory, Research, and Clinical Applications (pp. 395-433). New York: Guilford Press.

Juffer, F., Bakermans-Kranenburg, M. J., \& Van IJzendoorn, M. H. (2005a). Enhancing children's socio-emotional development: A review of intervention studies. In D. M. Teti (Ed.), Handbook of Research Methods in Developmental Psychology (pp. 213-232). Oxford: Blackwell Publishers.

Juffer, F., Bakermans-Kranenburg, M. J., \& Van IJzendoorn, M. H. (2005b). The importance of parenting in the development of disorganized attachment: Evidence from a preventive intervention study in adoptive families. Journal of Child Psychology and Psychiatry, 46, 263-274.

Juffer, F., Bakermans-Kranenburg, M. J., \& Van IJzendoorn, M. H. (in press). Introduction and outline of the VIPP and VIPP-R program. In F. Juffer, M. J. Bakermans-Kranenburg, \& M. H. van IJzendoorn (Eds.), Promoting Positive Parenting: An Attachment-Based Intervention. Mahwah, NJ: Erlbaum.

Juffer, F., Hoksbergen, R. A. C., Riksen-Walraven, J. M. A., \& Kohnstamm, G. A. (1997). Early intervention in adoptive families: Supporting maternal sensitive responsiveness, infantmother attachment and infant competence. Journal of Child Psychology and Psychiatry, 38, 1039-1050.

Klein Velderman, M., Bakermans-Kranenburg, M. J., Juffer, F., \& Van IJzendoorn, M. H. (in press). First impressions count: Process evaluation and case study of VIPP and VIPP-R. In F. Juffer, M. J. Bakermans-Kranenburg, \& M. H. van IJzendoorn (Eds.), Promoting Positive Parenting: An Attachment-Based Intervention. Mahwah, NJ: Erlbaum.

Kochanska, G. (1995). Children's temperament, mothers' discipline, and security of attachment: Multiple pathways to emerging internalization. Child Development, 61, 597-615.

LaFreniere, P. J., \& Capuano, F. (1997). Preventive intervention as means of clarifying direction of effects in socialization: Anxious-withdrawn preschoolers case. Development and Psychopathology, 9, 551-564.
Lieberman, A. F., Weston, D. R., \& Pawl, J. H. (1991). Preventive intervention and outcome with anxiously attached dyads. Child Development, 62, 199-209.

Main, M., \& Solomon, J. (1990). Procedures for identifying infants as disorganized/disoriented during the Ainsworth Strange Situation. In M. T. Greenberg, D. Cicchetti, \& E. M. Cummings (Eds.), Attachment in the Preschool Years (pp. 121-160). Chicago: University of Chicago Press.

Marvin, R. S., \& Britner, P. A. (1999). Normative development: The ontogeny of attachment. In J. Cassidy \& P. R. Shaver (Eds.), Handbook of Attachment: Theory, Research, and Clinical Applications (pp. 44-67). New York: Guilford Press.

Pearson, J. L., Cohn, D. A., Cowan, P. A., \& Cowan, C. P. (1994). Earned- and continuous-security in adult attachment: Relation to depressive symptomatology and parenting style. Development and Psychopathology, 6, 359-373.

Richters, J. E., Waters, E., \& Vaughn, B. E. (1988). Empirical classification of infant-mother relationships from interactive behavior and crying during reunion. Child Development, 59, 512 522.

Rothbart, M. K. (1981). Measurement of temperament in infancy. Child Development, 52, 569-578.

Rothbart, M. K. (1986). Longitudinal observation of infant temperament. Developmental Psychology, 22, 356-365.

Sroufe, L. A., Egeland, B., Carlson, E., \& Collins, W. A. (2005). The Development of the Person: The Minnesota Study of Risk and Adaptation From Birth to Adulthood. New York: Guilford Press.

Suomi, S. J. (1999). Attachment in rhesus monkeys. In J. Cassidy \& P. R. Shaver (Eds.), Handbook of Attachment: Theory, Research, and Clinical Applications (pp. 181-197). New York: Guilford Press.

Van den Boom, D. C. (1994). The influence of temperament and mothering on attachment and exploration: An experimental manipulation of sensitive responsiveness among lower-class mothers with irritable infants. Child Development, 65, 1457-1477.

Van IJzendoorn, M. H. (1995). Adult attachment representations, parental responsiveness, and infant attachment: A meta-analysis on the predictive validity of the Adult Attachment Interview. Psychological Bulletin, 117, 387-403.

Van IJzendoorn, M. H., \& Kroonenberg, P. M. (1990). Crosscultural consistency of coding the Strange Situation. Infant Behavior and Development, 13, 469-485.

Verschueren, K., \& Marcoen, M. (1999). Representation of self and socioemotional competence in kindergartners: Differential and combined effects of attachment to mother and father. Child Development, 70, 183-201.

Viswanath, K., Kahn, E., Finnegan, J. R., Jr., Hertog, J., \& Potter, J. D. (1993). Motivation and the 'knowledge gap': Effects of a campaign to reduce diet-related cancer risk. Communication Research, 20, 546-563.

Weinfield, N. S., Whaley, G. J. L., \& Egeland, B. (2004). Continuity, discontinuity, and coherence in attachment from infancy to late adolescence: Sequelae of organization and disorganization. Attachment and Human Development, 6, 73-97.

Received August 30, 2004

Revision received June 15, 2005 Accepted June 29, 2005 